WALNICE NOGUEIRA GALVÃO

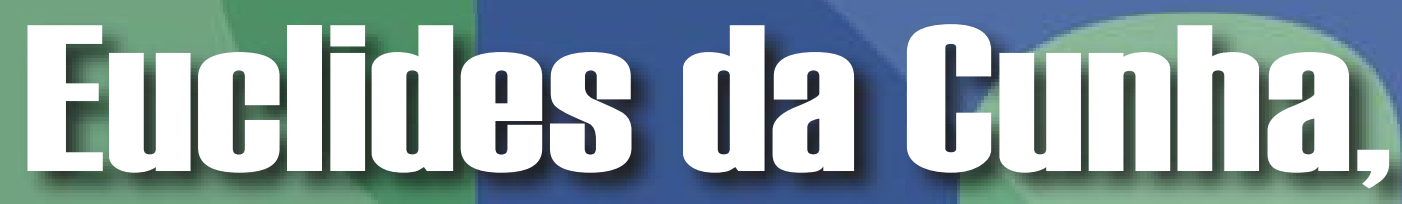

DJPHIIPSOP

WALNICE

NOGUEIRA GALVÃO

é professora da

FFLCH-USP e autora

de, entre outros,

Guimarães Rosa

(Publifolha). 


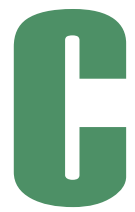

omo para comprovar que a história éfeita de paradoxos, Euclides da Cunha, ateu e antirreligioso, é o autor de um livro que viria a se tornar peça-chave dos estudos sobre nosso messianismo.

Sua obra será imperfeitamente compreendida se não for colocada contra o pano de fundo da Escola Militar, instituição de que foi um dos mais característicos frutos. Uma das primeiras de nível superior a serem instaladas no país, copiava o modelo da Polytechnique, realização da Revolução Francesa. Tinha por objetivo formar oficiais e engenheiros para os serviços públicos civis, como construção de estradas, portos e pontes. É visível a influência da llustração, sobretudo graças à inclusão nos currículos das ciências físicas e naturais, então uma novidade. Fundava-se assim na remota colônia um centro de altos estudos de modelo ilustrado, o que teria consequências imprevisíveis.

A década que precede a Abolição e a República seria a de mais notável participação da Escola Militar na vida pública do país. As causas em que se empenha são o abolicionismo e o republicanismo, que, conjuntamente, levarão à queda do regime e à implantação da República.

A geração da Escola Militar a que pertenceu Euclides é aquela que viveu em cheio a renovação de todas as ideias. Religião católica, instituições monárquicas, escravidão, prestígio da grande propriedade rural, ecletismo filosófico e espiritualismo, romantismo artístico-literário, tudo isso seria levado de roldão por "um bando de ideias novas", nos termos de Sílvio Romero e João Cruz Costa. Os dias do Antigo Regime estavam contados. É nesse período de extraordinário ativismo político que Euclides se torna aluno.

Passado esse interregno tumultuoso, Euclides acabará por deixar o exército em 1896, aos 30 anos. Fará carreira como engenheiro funcionário público, embora 
atraído pela política e pelo magistério; quando morreu, aos 43 anos, era finalmente professor. Jamais deixaria de lutar para ter um papel mais direto, e não só técnico, nos destinos da República.

Em outra fase de sua vida, viria a escrever Os Sertões, livro no qual procura combinar duas vertentes de pensamento. A primeira é nitidamente determinista, vinda da Inglaterra com Buckle e da França com Taine, influências hegemônicas no Brasil da viragem de século. É consabido que o esquema de montagem do livro obedece aos ditames analíticos de raça, meioe momento. Concorrem para essa linha, extrapolados das ciências naturais e exatas para os fenômenos sociais, o evolucionismo spenceriano, o darwinismo racial e o positivismo de Comte e de Littré. A segunda vertente deriva da concepção dos heróis segundo Carlyle, justificados por esse autor como encarnações do espírito divino que levam a história avante: o que se acomoda mal com o ideário positivista, anticlerical e até antirreligioso de Euclides.

A partir desse quadro teórico, ou apesar dele, Os Sertões coloca-se como um livro precursor, posto na raiz do desenvolvimento das ciências sociais brasileiras nos anos de 1930 e 1940 . A coexistência de dois países - um litorâneo e adiantado, o outro interiorano e atrasado -, lição aprendida em Os Sertões, será mais tarde radicalizada em contradição ferrenha substituindo a noção de coexistência.

Esse foi o primeiro grande livro, com imediato êxito e divulgação, a trazer para a linha de frente do pensamento nacional a indagação das razões do atraso do interior do país e desse país com relação a outros.

\section{O BELO MONTE}

Sucessivas secas assolaram o sertão na segunda metade do século XIXe culminaram na famigerada de 1877 , causando uma crise econômica sem precedentes e um saldo final que ultrapassou os 100 mil mortos. Some-sea isso o fim do cativeiro em 1888 , que atirou ao desamparo milhares de ex-escravos, muitos dos quais iriamengrossar as hostes conselheiristas. Tudo isso constituindohúmus propício ao surgimento de líderes messiânicos e de cortejos de retirantes.

Quando começou a chamar a atenção, Antonio Conselheiro já se tinha transformado num penitente ou, como passaria a assinar, "O Peregrino". Certos traços passarão a ser reiterados quando dele falam: seu tipo físico de sertanejo, com barba e cabelo compridos; o hábito azul de brim americano; a aparência desmazelada; o regime ascético, pelo qual se privava de carne, jejuava e dormia no chão; as obras de construção e restauração em que se empenhava; o carisma - e, naturalmente, o perigo para a ordem constituída.

Já ia completar duas décadas sua peregrinação quando houve o primeiro desafio aberto dos retirantes capitaneados pelo Conselheiro às forças policiais, o que se deu em Masseté, no sertão da Bahia, em consequência de uma de suas iniciativas públicas, com sobretons políticos. Foi quando liderou em Bom Conselho, Itapicuru, Soure, Amparo e Bom Jesus, tudo no lapso de oito dias, em 1893, uma queima das tábuas com os editais dos novos impostos republicanos, os quais, como é óbvio, viriam sobrecarregar de gravames a economia de penúria dos pobres. Por todo o final do Império, alastraram-se pelo Nordeste os motins populares que receberam o nome genérico de "Quebra-quilo", pois o alvo das iras do povo eram os padrões de pesos e medidas, bem como as tábuas de editais, em que os novos impostos se materializavam. Tratava-se de um ato aberto de desobediência civil; por causa disso, a polícia baiana foi chamada e, no confronto, sairia derrotada.

A refrega de Masseté viria marcar um ponto de inflexão e deve estar na raiz da decisão de pôr um freio à errância, com o subsequente assentamento em Canudos. A essa altura, o andarilho Conselheiro já era reconhecido pelas gentes do sertão como um benemérito, que empenhava seu séquito em mutirões de boas obras.

As terras em que ficava Canudos não eram desertas e ali se erguia um povoado 
com esse nome. Havia uma parca agricultura de subsistência, consistindo principalmente de mandioca para farinha e de cana-de-açúcar para rapadura. Também, como até hoje, criavam-se cabras, único vivente capaz de não perecer na caatinga sem água e sem verdura. Era pouco, ou quase nada.

Mas nem todos eram miseráveis no séquito. Havia gente de posses, que liquidava seus bens para acompanharo Peregrino. Em pouco tempo ergueu-se na praça das igrejas um correr de casas, que ficou conhecido como a Rua das Casas Vermelhas, assim chamadas devido à cor das telhas, destacando-se visualmente do conjunto.

Duas igrejas, por sua vez, defrontavamse de dois lados da praça. A primeira era a de Santo Antonio ou Igreja Velha, mais antiga, cujo orago era epônimo do Conselheiro, benzida e inaugurada provavelmente em junho de 1893, coincidindo com o dia do santo a 13, com grandes festas que incluíram casamentos de cidadãos locais. A segunda, a do Bom Jesus ou Igreja Nova, cujo arremate a conflagração impediria, era muito mais ambiciosa e de maiores proporções. Pode-se aquilatar a força simbólica dessas invocações quando se sabe que o Peregrino também era chamado de Santo Antonio ou Santo Antonio Aparecido, e Bom Jesus ou Bom Jesus Conselheiro. A antiga capelinha de Nossa Senhora da Conceição, anterior à ereção de ambas as igrejas, passou a ser chamada de "Santuário", preservando o altar e abrigando inúmeras imagens de santos. Num quartinho anexo morava o Conselheiro; e ali seria sepultado.

Aoredordesse centro formado pelas residências dos abonados e pela praça das igrejas, divisavam-se poucos arruados, perdidos em meio à aglomeração indistinta de casebres. Cobertos de folhas de icó, eram edificados em taipa ou pau-a-pique, ou seja, barro reforçado com galhos ou ramos, arquitetura comum a toda a população pobre do Brasil. Os precários materiais de construção davam o tom à cidadela, tornando-a indistinguível tanto do chão quanto dos arredores, na mesma monotonia parda da caatinga.

Na vida cotidiana do arraial predominava a religião, embora fosse, como de hábito no sertão e por todo o interior do país, uma religião festiva. Já anteriormente, na fase nômade, a entrada do séquito nos lugarejos e povoados era assinalada pelo espoucar dos foguetes. Nada disso era incompatível com a austeridade preconizada pelo líder, da qual há abundantes testemunhos.

Havia dois ofícios religiosos diários, à madrugada e à noitinha, e periodicamente os conselhos, ou sermões de leigo, com data marcada, para os quais acorria gente até de longe, ansiosa por ouvir a palavra do Peregrino. Canudos tornou-se um centro de romaria, atraindo crentes que ali chegavam para pedir audiência e fazer doações. Mas o arraial mudaria seu perfil à medida que a guerra se avizinhava, quando começaram a afluir voluntários de todos os quadrantes. Seu número cresceria vertiginosamente após o início das hostilidades em 1896.

Embora não fosse propriamente uma comunidade igualitária, havendo distinção até visível entre mais ricos e mais pobres, dada pela aparência das casas, alguns traços de igualdade havia, e certamente conferidos pela religião comum. $\mathrm{O}$ mais marcante desses traços era a inexistência de propriedade privada da terra. Quem chegasse podia erguer seu barraco, sem pagar nada a ninguém. Segundo testemunhos, a capela possuía como doação uma légua em quadro, que se dispunha em seu entorno, e era nessa terra que os recém-chegados tinham permissão para se instalar. Alimentos, roupas e dinheiro eram recebidos em donativos pelo Conselheiro e repassados aos destituídos. Por toda a duração do arraial, emissários percorreriam o sertão solicitando esmolas em espécie ou em numerário, o conjunto das quais era por ele administrado.

Secundando o líder, havia a Guarda Católica, constituída por 12 apóstolos. Uniformizados, armados e municiados pelo Conselheiro, dele recebiam soldo. Postavam-se de sentinela defronte ao Santuário, onde residia o Peregrino, revezando-se de quatro em quatro horas.

Em seguida, vinha a Companhia do Bom Jesus ou Santa Companhia, bem mais 
numerosa. Contava cerca de mil cabeças, ou 800 homens e 200 mulheres, todos uniformizados em brim azul. Um cenáculo de beatas, chefiadas por uma mordoma, cuidava da administração da residência do Conselheiro, no Santuário. Ele, conforme se sabe, quase não comia, apenas o suficiente para se manter vivo mas em total abstinência.

\section{AS HOSTILIDADES}

As relações da Igreja Católica com o Conselheiro tinham sido indefinidas, no passado. Como ele não se arvorava a sacerdote, não pregava dentro das igrejas nem ministrava os sacramentos, nada usurpava. Além disso, seus mutirões para reparar igrejas e cemitérios implicavam poupança para a Igreja, que detinha essa responsabilidade. E suas campanhas de reavivamento, com realização de novenas e trezenas, traziam ganhos para os padres, que auferiam lucros para casar e batizar. Alguns vigários o detestavam, outros eram seus amigos. O padre Vicente Sabino dos Santos, vigário do Cumbe próximo, tinha até uma casa dentro do arraial. Mas essa situação logo mudaria, e a Arquidiocese de Salvador enviaria uma missão de dois padres capuchinhos, que ao regressar escreveram um relatório condenando Canudos sem perdão. Daí em diante, não mais poderiam contar com o beneplácito da Igreja, e esta se aliaria àqueles que clamavam pelo extermínio.

\section{$\bullet \bullet$}

Aquela que seria uma verdadeira guerra, de um país inteiro contra um minúsculo povoado perdido no fundo do sertão, começou de modo quase fortuito. Como a escassa vegetação da caatinga não fornece madeira para construção, os canudenses tiveram que comprar fora o tabuado de que necessitavam para a Igreja Nova, cuja edificação já ia adiantada. A encomenda foi feita e previamente paga a um negociante de Juazeiro, de que eram bons fregueses. Todavia, o negociante se recusou a entregar a madeira, e os conselheiristas, revoltados, mandaram dizer que iriam buscar a encomenda pessoalmente. Pedida proteção policial para Juazeiro ao governador, iniciaramse as hostilidades, que no total somariam quatro expedições.

Após o insucesso de duas expedições, o governador da Bahia, que hesitava em comprometer a soberania do estado, decidiu-se a apelar para o governo federal, alegando que o problema era demasiado grave para encontrar solução dentro da esfera estadual de poderes. A 3ํㅡㄹ Expedição redundaria numa debandada e num desastre, pois as tropas em fuga foram largando pelo caminho fardas, armas e munições. E que constituíram um maná caído do céu para os conselheiristas. Paupérrimos e vivendo uma subsistência de mínimos vitais, não tinham arsenal que valesse a pena mencionar. Lutavam com armas obsoletas, de armar pela boca, tendo por munição pregos e pedregulhos.

Hoje, há mais de cem anos de distância, e tendo-se noção tanto das reduzidas dimensões do conflito quanto das reais forças de que os conselheiristas dispunham, não dá para fazer uma ideia do pânico que se alastrou pelo país. Não se sabia muito bem se a ameaça equivaleria a uma invasão iminente por hordas estrangeiras ou a um cataclismo desencadeando forças da natureza. A opinião pública, apavorada, passou a ser habilmente orquestrada pelos jornais, sem dar-se conta dessa manipulação até após o término da guerra. A informação era tão tendenciosa que antes mereceria ser chamada de desinformação deliberada.

Convocada a toque de caixa, a $4^{\mathrm{a}} \mathrm{Ex}-$ pedição baseou-se no tripé tecnológico fornecido pela Revolução Industrial, que passaria a definir a guerra moderna: trem, telégrafo e jornal. O novo tipo de conflito usaria a estrada de ferro para mobilizar massas de tropas através de vastos territórios. Tal estratégia depende da instalação 
de uma linha de telégrafo até a base de operações, para transmissão das ordens de comando. E o jornal, valendo-se da rapidez das comunicações via telégrafo, é arma no controle da opinião pública.

\section{A JORNADA DE EUCLIDES}

Na qualidade de adido ao estadomaior do ministro da Guerra viajava Euclides da Cunha, engenheiro-militar reformado no posto de tenente, duplicado de enviado especial do jornal $O$ Estado de S. Paulo. Primeiro fenômeno de ampla cobertura de mídia no Brasil, a Guerra de Canudos contou com muitos correspondentes, quase todos militares, a maioria beligerantes.

Uma das posições ocupadas pelo exército no cerco ao arraial chamava-se Alto da Favela, e ali abundava uma planta com esse nome. O substantivo comum, tomado à botânica e transformado em topônimo, teria longa vida e passaria por outras metamorfoses. De volta ao Rio, as tropas receberiam permissão para edificar seus barracos nos morros desertos da cidade, ao primeiro dos quais dariam o nome de Morro da Favela, em lembrança do outro. Dali, o topônimo novamente se tornaria substantivo comum, mas mudando de significado, para designar todo tipo de aglomeração urbana de caráter precário.

Os canudenses destacaram-se pela estratégia baseada em táticas de guerrilha, notável pela originalidade e pelo talento de aproveitar o menor acidente de terreno, inclusive as duríssimas condições de vida na caatinga. Lances de bravura invulgar foram registrados por quem ali se achava. Entretanto, a superioridade material das tropas era esmagadora, e o poder de fogo dos rebeldes foi silenciando.

O arraial resistiu até o dia 5 de outubro, quando, e todos os relatos ressaltam o fato, tombaram seus últimos defensores - dois homens, um velho e um menino -, que continuavam a disparar de dentro de um fosso escavado na praça das igrejas.

\section{A LIÇÃO DA GUERRA}

O fim da guerra provocou uma reviravolta de opinião. Por um lado descobriu-se que só havia aquele foco, aliás irredutível, e que nada tinha a ver com uma tentativa de restauração da monarquia; por outro lado divulgaram-se os métodos escusos adotados pelo exército, que degolara sistematicamente os prisioneiros manietados.

Assistiu-se a um mea culpa generalizado, que acometeu muita gente e encontraria sua forma mais altamente elaborada em $O s$ Sertões; o que, à parte seus indiscutíveis méritos, tem muito a ver com seu êxito imediato e a glória que cobriu seu autor.

$O$ fato é que o levante conselheirista tinha sido visto como uma irrupção de atraso, ignorância e superstição de um Brasil profundo numa nação moderna, que uma fase de otimismo progressista trazido pela extinção do trono e do cativeiro parecia anunciar. $\mathrm{O}$ que em parte explica por que todos se apressaram a renegar os canudenses e a reivindicar irracionalmente seu extermínio.

Quanto ao exército, portara-se mal e sua conduta fora norteada por um equívoco. O oficialato aprendia na Escola Militar a concepção, advinda da Revolução Francesa, de que o soldado é um “cidadão armado". Sua missão seria mais civilizatória que bélica, devendo por isso

\section{Antonio Conselheiro em pintura de Israel Pedrosa}

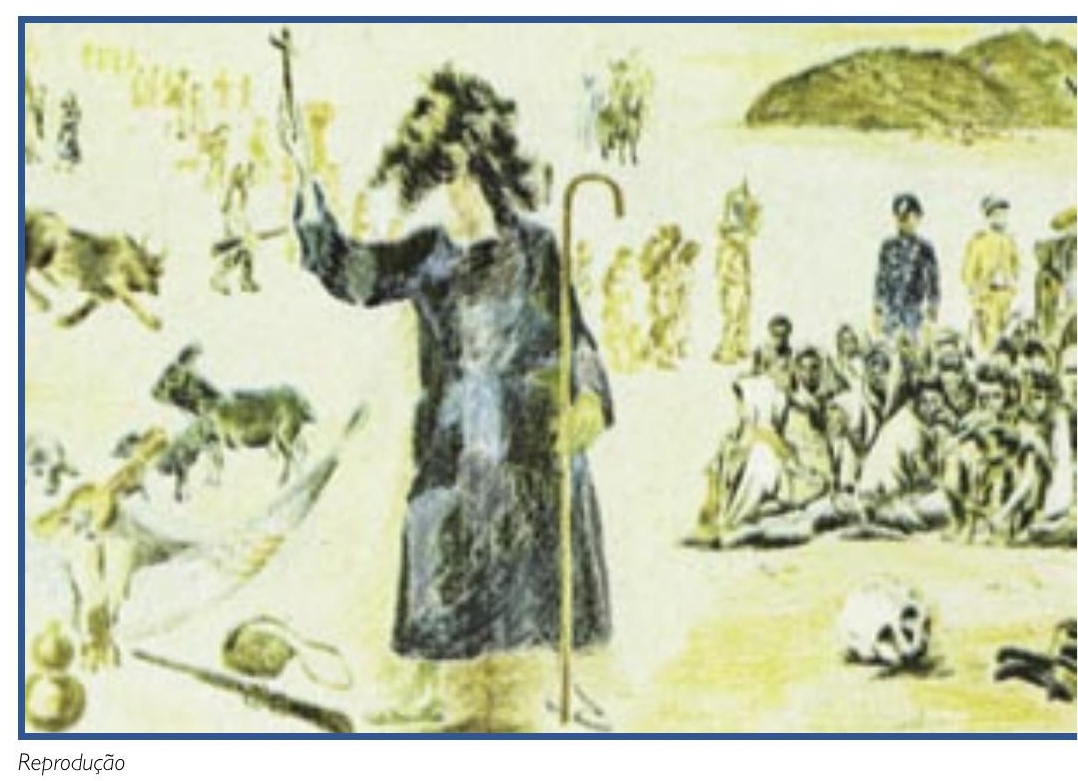


dedicar-se à difusão dos ideais revolucionários pela pregação e pelo exemplo. Foi o que as forças armadas acreditaram estar levando a Canudos. Por isso, não é de espantar a dimensão trágica que se atingiu, e que está exposta com todas as letras em Os Sertões, quando um exército que se considerava ao mesmo tempo a vanguarda e o braço armado do Terceiro Estado descobriu-se massacrando a plebe que o constituía.

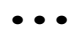

Alição principal que fica de uma guerra fratricida e desnecessária é a admiração pelo esforço desenvolvido por populações carentes de tudo para criar novas formas de vida em comum. De um modo ou de outro, engendraram uma estrutura alternativa de poder que as subtraía ao mando de fazendeiros, padres e delegados de polícia. No dizer de um militar que deixou seu testemunho, Antonio Conselheiro estava "fazendo da religião instrumento de governo".

Aparentada às guerras camponesas (Engels), aos processos de reencantamento do mundo (Weber), às rebeldias pré-políticas (Hobsbawm) e aos movimentos utópicos regidos pelo princípio esperança (Ernst Bloch), a Guerra de Canudos se ergue como um monumento a seus mortos, a perturbar a glorificação de nossa história. Ou, na súmula arrebatada de Euclides:

"Não lhes bastavam seis mil mannlichers e seis mil sabres; e o golpear de doze mil braços, e o acalcanhar de doze mil coturnos; e seis mil revólveres; e vinte canhões, e milhares de granadas, e milhares de shrapnels; e os degolamentos, e os incêndios, e a fome, e a sede; e dez meses de combates, e cem dias de canhoneio contínuo; e o esmagamento das ruínas; e o quadro indefinível dos templos derrocados; e, por fim, na ciscalhagem das imagens rotas, dos altares abatidos, dos santos em pedaços - sob a impassibilidade dos céus tranquilos e claros - , a queda de um ideal ardente, a extinção absoluta de uma crença consoladora e forte...".

\section{PERCURSO DE EUCLIDES}

Nas reportagens feitas por Euclides encontram-se os primeiros sinais de que sua inteligência está prestes a captar algum engano no ar. Penetrando no sertão e chegando até Canudos, o escritor vai gradativamente intensificando esses sinais e mitigando o entusiasmo patriótico que no início demonstrara, sem todavia perdê-lo de vez. Desviando-se dos demais repórteres, fará reflexões sobre o cunho equivocado da acolhida a bala dada aos canudenses, quanto outro tipo de tratamento mais civilizado poderia apaziguá-los. E dali a um palmo está o surgimento da admiração que por eles passa a manifestar.

No livro, após a radiografia do meio físico, examina aquilo que atribui ao sertanejo: o fanatismo religioso, a superstição, o equilíbrio psíquico instável, além de um considerável atraso com relação à marcha da civilização.

O determinismoque preside a essa minuciosa análise do meiofísico e dos componentes étnicos vê o processo eclodir na pessoa de Antonio Conselheiro. Com efeito, este constituiria uma síntese histórica oriunda das correntes de povoamento, através da miscigenação no isolamento.

O diagnóstico do Conselheiro é contraditório, o leitor percebendo a hesitação do autor entre considerá-lo um grande homem e decretá-lo “doente grave", afetado de paranoia. "Condensando o obscurantismo de três raças", a pessoa do condutor de povos "cresceu tanto que se projetou na História”.

Tentando elucidar a origem da Guerra de Canudos, Euclides mostra como o advento da República acarreta alterações que perturbam o ânimo dos conselheiristas: novos impostos, separação entre Igreja e Estado, liberdade de culto e instituição do casamento civil, que contradizia frontalmente um sacramento católico. 


\section{A SUMA SERTANEJA}

A Guerra de Canudos, como vimos, acabou por revelar-se a ignomínia de uma chacina de pobres-diabos. Tornou-se evidente que não houvera conspiração algumae que esse bando de sertanejos miseráveis não tinha qualquer ligação comos monarquistas instituídos - gente branca, urbana e de outra classe social, com horror a "jagunços" e "fanáticos"-, nem qualquer apoio logístico, seja no país, seja no exterior.

A reviravolta resultante foi notável: a opinião mudou de lado e passou a lamentar o massacre de valentes compatriotas numa luta fratricida. Ademais, deixou de ser segredo que a conduta do exército estivera longe de ser irreprochável. Começou a ser revelada a prática de degolar em público os prisioneiros indefesos, sancionada por todos, inclusive pelos comandantes.

Com a Guerra de Canudos, completase o processo de consolidação do regime republicano. Graças a ela, exorcizou-se o espectro de uma eventual restauração monárquica. Posteriormente, tendo à vista os testemunhos, pode-se dizer que a opinião pública foi manipulada e que os canudenses serviram de bode expiatório nesse processo. Desempenharam involuntariamente o papel de adversário comum a todos, aquele que se enfrenta coletivamente e que permite forjar a união nacional. À falta de um inimigo externo, capaz de promover a coesão do corpo social e político, infalível em caso de guerra internacional, suscitou-se um inimigo interno, com invulgar eficácia.

Para ligar os numerosos e heterogêneos materiais de que se serviu, Euclides tomou ainda emprestada dos canudenses messianistas e milenaristas - que ali se concentraram para esperar o Juízo Final anunciado pela chegada do novo século, numa vida de oração e penitência para salvar a alma - a visão escatológica. E mostra como, através da inversão demoníaca das imagens bíblicas que presidem à crença salvacionista, é possível aderir ao ponto de vista deles. Isso se efetiva através da mimese do grande sintagma narrativo da
Bíblia, por meio do qual é traçado o arco que vai da criação do arraial de Canudos, o Gênese bíblico, até seu aniquilamento pelo fogo, o Apocalipse, em conjunção com as profecias das sagradas escrituras.

Euclides, por sua formação como engenheiro militar, era adepto do progresso e da ciência, o que já se vê na escolha da profissão. Nunca lhe tinha ocorrido que a modernizaçãoé causa de dores e perdas para os pobres, aos quais chacina sem piedade quando os encontra em seu caminho, seja para abrir uma estrada de ferro, para escavar uma barragem, ou mesmo para substituir uma monarquia por uma república. São todos, em diferentes instâncias, fenômenos de modernização.

Tanto Euclides acreditava nela que termina por condenar a guerra, afirmando que os canudenses deviam ter sido tratados a cartilha e não a bala, concluindo pela falácia ilustrada de ver na educação a panaceia para a iniquidade. Seu grande feito foi ter conseguido expressar (e nisso reside o alcance universal do livro) o que a modernização faz aos pobres, atormentando-os de tal maneira que seu mundo - o Belo Monte na denominação que deram a Canudos, a Nova Jerusalém nas palavras de Euclides -, que tinha tudo para ser o paraíso no qual aguardariam o Juízo Final, metamorfoseia-se no seu contrário, ou seja, no inferno.

Era assim que os canudenses encaravam sua sina. Coerentemente, nessa visão escatológica, o imaginário apocalíptico, baseado no dogma salvacionista, sofre uma inversão demoníaca. A Cidade de Deus, um quadriculado de ouro e pedras preciosas, degrada-se no labirinto cor de terra do arraial. O Cordeiro de Deus, que tira os pecados do mundo, transforma-se em bode, único animal ali existente. O Rio da Água da Vida, que corre no Paraíso, não é mais que o rio seco que passa por Canudos, o VazaBarris. A Árvore da Vida se transforma na árvore da morte - os garranchos sem seiva da caatinga. E assim sucessivamente. Essa era a visão dos canudenses, que Euclides soube captar, enformar literariamente e expressar. 